Reynolds, F., Vivat, B., \& Prior, S. (2008). Women's experiences of increasing subjective well-being in CFS/ME through leisure-based arts and crafts activities: A qualitative study. Disability \& Rehabilitation, 30(17), 1279-1288.

\title{
Women's experiences of increasing subjective well-being in CFS/ME through leisure-based arts and crafts activities: a qualitative study
}

\author{
Abstract \\ Purpose: To understand the meanings of art-making among a group of women living \\ with the occupational constraints and stigma of CFS/ME. The study explored their \\ initial motives for art-making, and then examined how art-making had subsequently \\ influenced their subjective well-being. \\ Method: Ten women with CFS/ME were interviewed; three provided lengthy written \\ accounts to the interview questions. \\ Findings: Illness had resulted in devastating occupational and role loss. Participants \\ took many years to make positive lifestyle changes. Art-making was typically \\ discovered once participants had accepted the long-term nature of CFS/ME, \\ accommodated to illness, and reprioritised occupations. Several factors then attracted \\ participants specifically to art-making. It was perceived as manageable within the \\ constraints of ill-health. Participants also tended to be familiar with craft skills; had \\ family members interested in arts and crafts, and some desired a means to express \\ grief and loss. Once established as a leisure activity, art-making increased subjective \\ well-being mainly through providing increased satisfaction in daily life, positive self- \\ image, hope, and contact with the outside world. Participants recommended provision \\ of occupational/ recreational counselling earlier in the illness trajectory. \\ Conclusions: Creative art-making occurred as part of a broader acceptance and \\ adjustment process to CFS/ME, and allowed some psychological escape from a \\ circumscribed lifeworld.
}




\section{Introduction}

Chronic fatigue syndrome/ myalgic encephalopathy (CFS/ME) has a highly deleterious effect on everyday roles and occupations, through symptoms which include severe persistent or relapsing fatigue lasting for at least six months, and which worsens after exertion ${ }^{1}$; poor sleep; cognitive difficulties; muscle pain; headache; and extreme sensitivity to environmental stimuli ${ }^{2}$. Many people with CFS/ME also report social difficulties, because they commonly encounter high levels of disbelief and stigma in relation to their condition ${ }^{3}$. Faced with this array of physical, cognitive and social problems, people with CFS/ME typically report poor levels of subjective wellbeing ${ }^{4,5}$, very low levels of satisfaction with life as a whole, and particular dissatisfaction with leisure activities ${ }^{6}$. A key issue, according to personal accounts of CFS/ME, is to find ways of living satisfactorily within a very restricted context: 'to live as fully as I can in a body that cannot go very far' ${ }^{7, p .50}$.

Few people who are severely affected by CFS/ME fully recover physically ${ }^{8}$ but selfmanagement interventions help to improve subjective well-being. Such interventions typically include cognitive behaviour therapy (CBT) and graded activity, and have been shown to reduce pain after exercise and emotional distress ${ }^{9} \cdot \operatorname{Cox}^{9}$ also showed that lifestyle management helps people with CFS/ME to maintain activity and accommodate lifestyle to illness. However, few intervention programmes have specifically addressed quality of life in $\mathrm{CFS}^{10}$, or more specifically, the leisure occupations that may restore meaning and self-esteem.

Some intervention programmes have been designed to help people affected by CFS/ME to return to work ${ }^{11}$. However, some perceive regular work as too physically taxing $^{4}$. Leisure activities that can be carried out within the limits of available energy 
or functional capacities might therefore provide an important compensatory source of subjective well-being, as noted by some disabled people ${ }^{12,13}$. Stebbins ${ }^{14,15}$ presented the concept of 'serious leisure'. Practitioners who engage in this form of leisure experience high levels of obligation to their pursuit, perseverance, acquisition of specialist skills, and entry into new social worlds. This concept accounts well for some of the psychological benefits of art-making described by people living with diverse chronic illnesses ${ }^{16,17}$. Yet how people encounter and incorporate new leisure pursuits into their lifestyles after the onset of ill-health, has been little explored.

In the specific context of CFS/ME, Hart and Grace ${ }^{18}$ found that people described specific psychological turning points, including changing attitudes to, and relationships with, the illness. Yet whether turning points were associated with new meaningful activities remained unclear. Gray and Fossey ${ }^{19}$ pointed out that little research explores whether and how people with CFS adapt their own occupations after becoming unwell. They interviewed five individuals who had lived with CFS for between 2 and 10 years. One theme which emerged from the interview data was the subjective importance of activities. Participants differentiated good days from bad

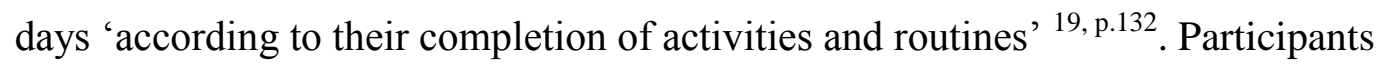
were actively engaged in strategies such as pacing and relaxation to enable them to carry out everyday activities and maintain a positive attitude. Some resisted being defined by their illnesses by embracing 'new directions, new interests' 19,p.132. Participants 'regarded activity as "the key" to maintaining well-being, fostering a sense of enjoyment, purpose and control, and utilising their capacities,' and the authors therefore recommended further research to understand how people re-enter occupations ${ }^{19, \text { p. } 134}$. This recommendation was acted upon in this study. 
This qualitative study focused on the experiences of women with CFS/ME who had taken up or substantially intensified their participation in art-making after becoming ill. The study addressed two questions. Firstly, why did participants with CFS/ME turn to art-making after the onset of illness? Secondly, once leisure-based art-making had been incorporated into daily lifestyles, how did it influence participants' subjective well-being?

In this study, the term 'art-making' is used to describe a range of arts and crafts, including painting, pottery, card-making, embroidery and tapestry, carried out at any level of expertise as a leisure activity.

\section{Method:}

A phenomenological approach was appropriate for exploring the lived experience of CFS/ME and the experiences that led up to, and followed on from, the discovery of art-making as a meaningful leisure occupation. The study followed principles of interpretative phenomenological analysis (IPA). Smith, Osborn and Jarman 20, p. 218 describe IPA as 'concerned with an individual's personal perception or account' rather than objective or factual statements about events. This approach seeks to understand participants' beliefs and feelings, whilst acknowledging that any account is likely to be partial and shaped in part by the dynamics of the interaction. IPA studies vary from highly idiographic, presenting detailed analysis and interpretation of the nuances of meaning from a small number of cases ${ }^{\text {e.g. } 21}$ to more thematic, placing more emphasis on the common experiences of larger samples ${ }^{\text {e.g.22 }}$. In this study, we focused more upon the shared aspects of the lifeworld, as described by participants. 


\section{Ethical approval}

The Ethics Committee at the host institution scrutinised and approved the project proposal, information sheet, consent form, main interview questions and advertisement for volunteers, before any contact was made with participants.

\section{Participants}

Potential participants were recruited from two sources. Twelve responded to invitations placed in the letters pages of creative arts magazines, and one responded to an invitation placed in a newsletter for a local CFS/ME support group in the London area. The study was described as seeking participants who would be willing to describe their experience of art-making in the context of living with chronic illness. Those who expressed interest in the study were sent full information, including the main interview questions, and gave written consent. Most people who requested the information pack volunteered to participate. The only exclusion criteria related to age (participants had to be 18 years or over) and language use (fluency in English was required). Only women volunteered. In line with other phenomenological studies, participants' reports of their own diagnosis were accepted without independent medical confirmation.

Ten women wished to be interviewed and a further three women preferred to submit lengthy written answers to the questions on the interview guide, perceiving this method to be more easily self-paced. All participants had lived with CFS/ME for at least 5 years.

The age range of participants was 34-62 years, with most in their 50s. Nine lived with husbands or partners and four were single/ divorced. All were well educated. Twelve 
had previously been employed in a professional job (e.g. as an administrator, nurse, radiographer, teacher), but all had retired since the onset of their condition.

\section{Qualitative interviews}

The semi-structured interviews were mostly completed in about one hour (the range was 50 minutes to two hours, with breaks to look at artwork in the home). All were carried out by the first author, audio-recorded and professionally transcribed. The interviews explored participants' experience of illness, including its onset and trajectory; their reflections on why they had taken up art-making; and the ways in which visual artmaking as a leisure occupation contributed to their subjective well-being and coping with CFS/ME.

The main questions were as follows, with additional probes as needed:

1. Please describe some of the ways in which your health and day-to-day life have been affected by CFS/ME.

2. How did your interest in the visual arts begin?

3. Can you describe what is satisfying about creative activity?

4. Do you think that your artwork has helped you to express your feelings about your illness - or not? What other inspirations do you express in your artwork?

5. In what ways has your artistic work helped you to manage/ live with your health problems?

6. Do you have suggestions for making art more accessible for people with health problems?

Fieldnotes were recorded after each interview, to aid conceptual analysis. In the quotations that follow, ellipsis (...) indicates where they have been edited for brevity. 


\section{Data analysis}

Coding of themes proceeded iteratively. Following advice for the conduct of IPA ${ }^{20}$, one particularly rich interview transcript was selected for initial detailed coding. Each author provided an independent analysis and met to resolve any differences in interpretation. As subsequent transcripts, and the written accounts, were analysed, additional themes were added. This article focuses on the main recurring themes, relating firstly to the initial discovery of art-making as a meaningful occupation in CFS/ME, and secondly its influence on subjective well-being once part of the women's everyday lifestyles. The different professional backgrounds of the researchers enriched the process of analysis and interpretation (as noted by previous researchers ${ }^{\text {e.g.23 }}$ ) and supported its confirmability.

\section{Findings}

Participants' accounts confirmed previous research into the experience of CFS/ME, describing significant problems such as loss of concentration, fatigue, stigma and difficulties in maintaining work, leisure and family roles. These problems had highly negative influences on quality of life. In the early years of illness, alternative occupations that could be accomplished within the limits of health were difficult to find.

I spent an awful lot of time ... without doing anything much at all ... I was really scrabbling around, because I got fed-up watching television. I really didn't have anything very much to occupy me and I really did go through a very low period.

None of the participants had engaged in art-making as a 'serious' or committed' leisure activity until after the onset of CFS/ME. The reasons that participants gave for turning to arts and crafts as a way of living with their health problems will be explored next. 
Why did participants with CFS/ME turn to art-making after the onset of illness?

Participants had not been lifelong artists in their leisure time, so why and how they had turned to art after the onset of CFS/ME was highly relevant to understanding the process of lifestyle adjustment and occupational re-entry. According to their accounts, participants did not casually or suddenly encounter artistic pursuits. Rather, most described taking up art-making after a long struggle to accept the long-term nature of CFS/ME and to accommodate their lifestyles. Psychological acceptance released more active coping strategies which included reframing their leisure time, and exploring certain feasible artistic pursuits. The main features of this discovery process are explored in more detail next.

\section{Accepting the long-term nature of CFS/ME}

Many participants said that a key turning point in living with CFS/ME, which ultimately facilitated their interest in art-making, was associated with acceptance of the long-term nature of the illness:

Acceptance is the key.

Nevertheless, acceptance was a slow and difficult process. For example, one participant took seven years to admit that she had ME. Up until that point:

I was fighting it, I wouldn't give in to tiredness, I wouldn't give in to the aches, and I wouldn't let it stop me because I've always been an active person and that was incredibly hard, but then I had to give in ... and that was the big change.

So acceptance often followed a considerable period of emotional and physical struggle, during which participants maintained hope of recovery, sought medical treatments, and attempted to return to valued occupations. Yet once they had accepted that the condition 
was likely to be long-term, they were more able to accommodate to the limitations that illness imposed on daily life. One reflected back on 16 years of ME:

I just learned that if I didn't live within my capabilities regarding my health, then I was going to have an even more miserable life than how I felt at the time, because at least if I lived within my ME, I did have good days and those good days were very precious and that's how I live now... yes, it is pacing and being very aware of how you feel.

Pacing enables preservation of some roles and activities. Yet it is a strategy that also risks defining the person as ill and functionally limited.

\section{Devising active coping strategies for living with illness}

Positive decisions to live with illness (rather than striving for recovery) released more active strategies for coping with the effects of CFS/ME on daily lives. For some, initial objectives were very modest indeed:

I was literally stuck in bed and I'd lost all my strength and I could hardly do anything and you just think, well, what can I do? That's what goes through your mind, it's an order not to completely lose the sense of who you are and your sense of self ... It was very difficult to keep the house going and make the meals and all that sort of thing... and I just thought... if I can just sew one seam today, that will be wonderful and that's the level it was.

Participants described a range of active strategies for living with CFS/ME, including: officially retiring from work (by the few who were continuing with some form of paid work), seeking complementary therapies, revising priorities including reframing leisure time, and identifying leisure activities that would enhance their quality of life within the limits of physical and cognitive functioning. Recourse to art-making was 
one strategy among several leisure and lifestyle adjustments that participants deliberately made in order to live more positively with CFS/ME.

I started going in for complementary medicine, first of all Reiki healing and homeopathy ... I'm learning to control it. It still has a major bearing, but I don't feel like I'm a sufferer, I feel I've got some control over it although sometimes it gives me a kick just to remind me that it's there.

Another participant who had lived with ME for more than 10 years had gradually devised many health promoting strategies, including art-making:

In the early stages I could have given in to it [ME], but I'm not doing that now ... I mean ME, one of the most visual analogies is, you're like a boat with a hole in it and you've got to keep that boat above the water. If it goes below the water ... you've got to lighten the cargo, so that the whole thing stays above the waterline. ...You can't, of course, have a stress free life, but there might be various strategies... I mean I don't drink alcohol, I try and be sensible about my diet, I don't smoke. At the moment I'm on a fairly low carbohydrate diet, but not obsessively. And I try to say "no" to things and also importantly, I attend Quaker meetings and I find that very helpful in a spiritual sense. But art, I think, is also very spiritual.

\section{Turning to art-making}

The protracted psychological process of coming to terms with the long-term nature of CFS/ME, including finding ways of living more fully within its constraints, would not have led participants inevitably to initiating creative leisure activities. So why did these participants initially choose to engage in art-making as a leisure occupation? Four main reasons were identified. 
Availability of pre-existing craft skills: Participants had all acquired practical craft skills (notably dress-making) prior to their illness. They did not necessarily use these specific craft skills after becoming ill, but seemed to retain some confidence in their manual dexterity. Their accounts often portrayed the self before illness as active, 'always busy doing'. Some described themselves as unable or unwilling to sit still and concentrate on reading or television. Once they had accepted the need to accommodate their lifestyles to their illness, they sought refuge in a familiar pattern of behaviour, which was to use their manual dexterity and make something. Art-making also represented a source of continuity in their lives, helping to mend the disjunction brought about by illness, as family members had also tended to engage in crafts and clothes-making. One participant recounted what attracted her to artistic pursuits after becoming ill:

My mother did some knitting ... She sewed all our clothes as kids and she did a really super job, a super job. Her sister, my aunt, she was brilliant at knitting and embroidery. Dad used to sketch from time to time and a little bit of painting, so I was always surrounded by craft.

Another suggested:

I was definitely influenced by my mother, yes. She sewed, she did dressmaking ...I mean it was part of my bringing up.

Craft skills could be understood as providing a form of capital that participants drew upon and adapted to engage in small artistic projects, as explored next.

\section{Art-making was perceived as a manageable activity within the constraints of}

\section{CFS/ME.}

Participants perceived many leisure occupations as requiring far too much cognitive and physical resource. Art-making initially attracted them because it offered controllable opportunities for making small, easily handled items, during short periods of activity. 
One of the most severely affected participants had lost most of her adult roles to illhealth. In addition to profound fatigue she experienced many other symptoms of CFS/ME such as sensitivity to environmental stimuli. Yet she gradually realised that watercolour painting was a feasible occupation:

'I've never been an artistic person...I realised, when I was beginning to get a bit better after what I call the first bout of ME, about six years after the onset, I've always been a creative person. But of course I had to stop all that when I first became ill and then I thought... it would help me to do something creative if I can find something that isn't going to exhaust me and I hit upon watercolour painting, because that was actually the least tiring thing that I could think of. Just using tiny brushes, they don't smell of paint, because I'm very sensitive to chemicals. So, it was a bit of watercolour painting, just really to put some colours on paper, you know. I wasn't even trying to do anything like a proper painting or express ideas or feelings, it was just a creative thing of putting colours on the paper'.

Small arts and crafts projects offered manageable and satisfying ways of filling the occupational voids created by CFS/ME, and offered opportunities to be creative. A few, as noted below, wished to express their feelings about illness through their art, but most simply wished to be more active and engaged in meaningful occupation.

Art-making was perceived as a means of emotional exploration and self-expression. Although most of the sample did not describe any clear psychotherapeutic motive for turning to art-making, this was a significant impetus for three participants. They described being initially attracted to art to explore the emotional impact of CFS/ME. 
They believed that, even though conducted as a 'leisure' activity, art might offer a potent therapeutic means of self-expression.

I realised that I wasn't coping at all really emotionally with things and that was very helpful to clarify exactly what my feelings were, because I think when you're very ill you haven't got the energy to clarify and deal with it anyway. I totally just suppressed it all.

Notably two of these three had engaged in verbal psychotherapy after the onset of CFS/ME and this experience may have encouraged them to perceive art in therapeutic terms.

In summary, most participants turned to art initially after a long process of coming to terms with the chronic nature of their conditions, and perceiving a need for lifestyle adjustments. They were not a specialist group of artists, nor did they have artistic training or highly unusual family backgrounds. Once ready to make lifestyle changes, they were initially attracted to art-making largely because familiar with making aesthetically pleasing items (usually clothes), and had observed family members who were skilled in some crafts (such as knitting). Art-making offered small projects which could occupy empty time after participants had left work, or lost other roles. A few turned to art to express emotions about their illness.

\section{Once established as a regular leisure occupation, how did art-making influence} subjective well-being in the context of CFS/ME?

All participants experienced art-making as increasing their subjective well-being, at least to some degree, and as helping them to tolerate the limitations imposed by CFS/ME. 
I don't think it [art-making] helps health-wise in any way, but it's quality to life.

Self-esteem, and emotional well-being benefited from committed engagement in artmaking:

Looking for form, colour, movement, relationship, light, and harmony or clash, helps me redefine meaning in my much-diminished life and has kept me from suicide (written narrative).

Participants all felt that leisure-based art had enhanced the quality of their everyday life in many ways. The three participants who took up art initially to express their grief and anger about CFS/ME felt that it had indeed provided these benefits. But for most participants, art-making came to be valued for promoting satisfaction, an improved self-image, hope for the future, and stronger contact with the healthy outside world, all important achievements for those whose lives were severely constrained by ill-health. These themes are now explored in turn.

\section{Art-making increases satisfaction with daily life}

Participants all emphasised that their artistic leisure activities had enhanced their subjective well-being in the context of living with CFS/ME. They described feeling more satisfied with their daily lives through gaining purpose, challenge, and achievement in a context that offered few alternative sources of reward:

I have a contentedness that I didn't have before. I can always be busy and occupied no matter how ghastly I feel. My husband and daughter have both remarked on it. I don't harangue my husband as I used to. I know now that was due to my constant frustration at not being able to get out and about and do a lot (written narrative). 
Some disclosed that they were sometimes willing to exceed their limits of energy and muscle strength in pursuing their creative activities, because of the satisfaction they derived from the activity:

I am paying a price for it, but it's absolutely essential and I will pay that price, because it more than pays back for me in satisfaction. If I didn't do it, if I wrapped myself up in cotton wool, I might have a more even health, but it would be dark grey.

Colour within the artwork itself had positive effects on emotional state, through both its direct stimulus and its capacity to trigger positive memories about life and self before illness. One participant who had done voluntary work in Africa prior to her illness said of a textile piece:

It was a very joyful piece... The colours are like balls of sun and very much African colours.

Art-making enhances self-image and self-confidence

CFS/ME was experienced as highly threatening to self-image and identity. With loss of so many roles and valued occupations, many participants had experienced worthlessness. Their art-making - even when practised for short periods - helped to counter this experience, at least to some extent.

If you have ME or chronic illness or whatever, you almost feel that you need to produce something to manifest your aliveness, otherwise life just becomes completely chores and it's as though you need concrete proof of, look, I can do this, my soul hasn't died. You know, I think that's the main thing why one does it. 
Art-making helped participants, in varying degrees, to meet their needs for achievement. Most participants had given up work as a result of their condition, and experienced a long period of low self-esteem and even shame in not being able to perform their normal roles.

You lose your sense of self worth, because you're feeling to yourself, I'm not doing it [housework] as well as I ought. So ... that's what took me a really long time, finding out ways that I could feel, well, I've achieved something.

One participant who had lived with ME for more than 20 years described how her artmaking helped her to counteract the stigma associated with the illness:

I seemed to have gained a perspective about myself and a kinder understanding and acceptance of my limitations without subjecting myself to constant criticism as I did in the past. I no longer worry what other people think. I know the truth of the situation regarding my health and this creativity I have tapped in to is a joyous kernel of something that can't be taken away from me (written account).

Self-confidence was partly related to the visibility of the artwork, which offered some proof of the participants' skills and persistence both to self and others:

If I hadn't this work I would have NOTHING to show for living eight years. (written narrative).

I think the biggest value is to have something concrete which you can show people that you've done, that's one thing. Also it's good for self esteem, it's good for confidence. 
However, several participants cautioned that to maintain their well-being, they needed to celebrate their current abilities, rather than making negative comparisons between their achievements before and after the onset of CFS/ME.

I have found this other way of moving forward... and not being too down about the things from the past. To find something that you can do that's within your capabilities and not thinking all the time, well, I could do this before, and now [I can't] ...It makes you feel as though you are achieving something.

Art-making encourages hope for the future

Participants regarded their art-making as helping to create hope for the future, as they looked forward with interest to further projects, rather than feeling totally trapped by functional limitations and defined by their ill-heath.

Being creative helps me to keep my mind off me, and that bit that hurts, or being fed up that because I'm ill, I can't really do what I want to do. So I can see now a future which two years ago I couldn't.

However, most refused to look too far ahead, in order to avoid feeling dispirited by the prospect of chronic illness. Few had ambitious plans, preferring to focus on projects that would be both be manageable yet and meaningful within their physical constraints. For example, one participant who was often confined to bed used her creative photography to set herself short-term goals, describing her desire: to stay alive at least until the next roll of film comes back developed to see how the pictures look and to whom I can send some. So I make sure there's always another roll around to start using when the opportunity presents. (written account) 
Another wrote about her need to temper creative aspirations with realism about her health:

Ideas for future work stretch forever. That is what keeps me alive quite simply, after my children of course. The ideas keep inspiring me. I just crave more energy to give them life and make the image more powerful or memorable ...I've stopped looking for miracles... I prefer not to concentrate too far ahead, it's dangerous. Living one day at a time is best for me - I must listen closely to my body (written account).

Art-making provides contact with the healthy outside world:

Participants experienced CFS/ME as seriously curtailing everyday activities. Many were confined to home and even to bed for extensive periods. Some became lightsensitive and drew the curtains during daylight hours. Many reported losing contact with family and friends who could not cope with their limitations. Living within such a circumscribed physical and social environment, perhaps it is not surprising that many participants expressed a need to have contact with the 'healthy' outside world. Their art-making afforded some contact, even if only limited, or through imagination. I loved to walk. Now I can take the memory of past walks and build it into my work. I can get out all my photos and work from them.

The art means that I just feel I have a life. My life now is not external, really. I do go out a bit, but a lot of my life is lived within my flat, but when I'm doing my art, I'm out there, I'm at the top of the hill or I'm down by the lake or I'm way, way away in Africa or whatever, even though physically I can't do a lot of those things. 
A few of the most severely affected were able to appreciate their immediate environments in more interesting detail, alleviating boredom:

Doing this [art] has given me a sense of richness of my immediate environment (including the room I'm usually stuck in) which I did not have before. This layer of texture and detail - heightening- has been a factor in still surviving $M E$ (written account).

Furthermore, closer contacts with the immediate and outside environment also helped to counteract preoccupations with illness and debilitation:

What they (pictures) express is the affinity that I feel with the country or with flowers, trees, the natural life, which, when one is housebound or almost housebound, you can't actually express by being out there, by walking... If you've been ill or not well for so long, you lose confidence in your body. You lose the feeling of integrity within your body and so anything outside your body that retains its health and integrity is focused on and marvelled at in a way that people who haven't perhaps been as ill don't fully understand and appreciate.

\section{Lifestyle counselling: a perceived gap in services}

The interview concluded by asking participants if they had suggestions for increasing the accessibility of arts and crafts for people affected by their condition. Many responded by commenting on the general lack of professional advice they had received about how to live more positively with CFS/ME. Initial contacts with health professionals had focused upon diagnosis and medical interventions, and participants felt that they had not been equipped with the attitudes, strategies or occupations that they needed for coping with the devastating effects of the condition on their everyday life. Most had taken years to make some positive lifestyle adaptation, through their 
own efforts at accommodating to illness and developing meaningful leisure pursuits. They suggested that more advice and counselling should be made available to people with CFS/ME, to help them to live more fully within the constraints of their illness, whether by taking up art-making, or exploring other feasible activities.

At no time, in all the time I've had ME, have I ever been offered any sort of counselling, occupational therapy, nothing. And looking back now, if someone had said to me, "Look, I have experience of being with people with similar illnesses to yourself and can I suggest you try this or this", I might have been able to start picking up the pieces a lot quicker. And if that person who had counselled me had said... “We're talking about a whole range of things you can do and if you can't already do these things we can adapt, [and] there are new skills” ... you might say, “Well, I can't do this tapestry, because I can't handle the area". They might say, "Well, why not do the little tapestries that you can make into Christmas cards for people?"? There doesn't seem to be that sort of advice for people with long term illness.

The plea for earlier advice to help rebuild quality of life was repeated by another participant:

The door could be opened to people earlier... sadly in the case of a lot of illnesses, then they might not get better, but at least they're looking back on whatever has happened during their illness and saying, '... I've left something behind'. It's very dramatic, but I feel that had I had the options or just someone to talk to me and say, "Well, look, stop thinking about what you've achieved in the past, look at your skills and see what you can achieve now. If you feel that's not appropriate, look at achieving other skills". It's just a sheer feeling of optimism, rather than pessimism. 


\section{Discussion}

Few people severely affected by CFS/ME fully recover and therefore they face the considerable task of adapting self and lifestyle to long-term physical constraints if they are to enjoy a more positive quality of life. This study has been unusual in exploring the process of occupational adaptation, specifically seeking to understand why participants initially turned to art-making as a leisure activity after the onset of CFS/ME, and its subsequent influences over their subjective well-being.

Like participants living with chronic illness interviewed before ${ }^{16}$, participants did not report a life-long commitment to art-making, but had turned to creative occupation after the onset of illness and a long period of struggle to retain work and family roles. One factor facilitating their turn to art-making related to having acquired certain adaptable crafts skills (such as dress-making skills, or tapestry) during childhood or adolescence. However, participants in the current study rarely continued with earlier (pre-illness) activities such as tapestry work as they had insufficient strength, energy and concentration. Instead, they sought out lighter artistic activities such as watercolour painting or card-making, which were more easily handled. As reported before $^{16}$, participants referred to the influence of family role models who had engaged in arts and crafts, and the sense of continuity that they derived. Art-making may have therefore helped to heal the biographical disruption brought about by CFS/ME ${ }^{24}$. However, unlike the previous study ${ }^{16}$, and possibly reflecting the current participants' generally greater functional impairment, very few mentioned being motivated initially by community arts projects or art classes.

There were further contrasts from the previous study in that many participants with CFS/ME reflected that their turn to art-making had occurred after a very long period of emotional and cognitive struggle. Perhaps reflecting the status of CFS/ME as a 
contested illness of uncertain cause and trajectory, they had spent many years striving to recover and seeking to preserve valued roles and occupations. These findings resonate with those of Whitehead ${ }^{25}$ who showed people with CFS/ME typically maintain long-term hopes that recovery will be possible.

As also reported by Hart and Grace ${ }^{18}$, many reflected that a key turning point in living with their illness had occurred when they accepted that their health was unlikely to improve. Having done so, they more willingly accommodated to their illnesses, and reprioritised their daily lives, reducing energy-sapping chores and introducing more satisfying activities. That acceptance of chronic symptoms may shift attention away from the body, towards everyday activities, thereby enhancing well-being, has been noted in other studies ${ }^{\text {(e.g. } 26)}$.

In exploring the influence of leisure-based art-making on subjective well-being, certain similar themes emerged as reported in a previous study ${ }^{17}$, which recruited participants with a range of chronic illnesses. A minority of participants in both studies explicitly used some of their 'leisure-based' art-making in a psychotherapeutic way, to explore grief, hopes and wishes about their lives. In the current study, prior or concurrent experience of verbal psychotherapy may have facilitated the use of art in a cathartic way.

Once established as a regular leisure activity, art-making supported subjective wellbeing in various ways. As noted before ${ }^{17}$, participants emphasised that art-making helped to maintain or restore self-image and self-confidence. These experiences have also been noted by Stebbins ${ }^{14,15}$ in his studies of 'serious leisure'. The participants with CFS/ME also seemed to emphasise certain benefits of art-making that were not widely shared by people living with other chronic illnesses ${ }^{17}$. Participants with 
CFS/ME placed more emphasis on deriving hope for the future, but some cautioned that short-term rather than long-term goals were preferable. Learning to live with CFS/ME included adapting to its ongoing constraints such as limited energy, concentration, and unpredictability. Compared with people living with other chronic illnesses ${ }^{17}$, these participants gave more emphasis to enjoying contact with the healthy external world from the confines of home through their art-making. Contact was rarely achieved in a physical sense, but through reviving memories, and sharpening appreciation of the environment within and immediately outside the home. This complements other studies that have found well-being to be enhanced by leisure activities that bring people into contact with the beauty of the natural world (e.g. review $^{27}$ ). Unlike some other studies of leisure benefits ${ }^{27}$, participants made little mention of gaining companionship, distraction or positive reappraisal. They did seem to find that art-making affirmed identity and expanded meaningful experiences within circumscribed lifeworlds.

Most participants had not only lived for many years with CFS/ME but had taken many years to adapt and rebuild a lifestyle that had some quality. This finding resonates with a previous study ${ }^{28}$ in which people with CFS/ME took on average six years to try a complementary therapy. In the current study, many argued that they would have adapted their lifestyles sooner, and with less emotional struggle, if they had been given more professional support in the form of occupational therapy or recreational/lifestyle counselling. Such input would be distinct from graded activity programmes or cognitive behavioural therapy, in helping participants to consider which new activities - feasible within the tight limits of physical and cognitive energy - would give meaning to life and which former activities could be adapted. 
Whilst the study illuminated the process of discovering art-making as a meaningful occupation, and identified its contributions to well-being, limitations remain. The study was based on a small sample, although similar in size to other qualitative studies $^{\text {e.g. } 18,23}$. Some of the data were in the form of written answers to the main interview questions. These data were highly relevant but could not be probed for meaning. However, it was considered advantageous to enable people to participate in whichever way they thought feasible within the constraints of their health (as advocated by other researchers into the CFS experience ${ }^{29}$ ). The written accounts, although more condensed, were rich in reflective insights, as shown in the extracts given above. They were not markedly more or less self-disclosing. We acknowledge that the sample was not in any sense random. Participants were well educated, almost all had professional jobs prior to illness, and may therefore have enjoyed particular psychosocial resources for adapting their lifestyles. Despite these advantages, it is notable that adaptation to CFS/ME remained difficult. One person was drawn from a support group and the others entered the study from a different source. However, there were no clear differences in participants' views or needs in relation to the source of recruitment.

Without a longitudinal design, it was not possible to discover whether some degree of physical improvement might have preceded participants' turn to art-making. However, most participants did not believe their symptoms had abated, and some even thought that their physical health had worsened. Other research has also detected psychological, rather than symptom-related, turning points in living with CFS/ME 28,30

This study has focused on recurring themes and general processes associated with adapting lifestyle to CFS/ME, but individuals also offered certain idiosyncratic 
perspectives. With a qualitative study, it is accepted that researchers use their own subjectivity throughout the research process. They are highly involved in coconstructing the narratives elicited in interview ${ }^{31}$ and the themes that are interpreted during analysis ${ }^{20}$. The study has yielded certain similar findings as previous research and yet also provided some new perspectives, indicating that the researchers have not been overly biased by any expectations brought to the study. The analysis was strengthened by the independent contribution made by the co-researchers who did not carry out the interviews.

\section{Conclusion}

A long period of emotional, cognitive and physical struggle was described in which participants with CFS/ME sought recovery and tried to preserve valued occupations. Once they accepted that their illness was likely to be long-term, they were more able to engage in accommodating lifestyle to their state of health, abandoning certain activities and reprioritising their daily occupations. None of the sample had been lifelong artists. Various personal craft skills and family role models seemed to encourage a turn to art-making as a way of living with CFS/ME, as did the view that small arts and crafts projects might be feasible and satisfying for people with limited energy and strength. Some turned to art to express feelings about their illness. Once established as a leisure activity, art-making provided a psychological escape from a physically and socially circumscribed lifeworld. Art provided new sources of satisfaction in daily life, improved self-image, hope for the future, and positive contact with the outside world. For a few, it also provided cathartic self-expression. More professional and informal support was called for to help people affected by this illness to make earlier positive lifestyle adaptations, including quality leisure experiences. These findings carry implications for health professionals who work with any client whose quality of life has been severely limited by fatigue and other intrusive symptoms. 
Acknowledgements: The authors are grateful to all participants for sharing their experiences and acknowledge the financial support of the Arts and Humanities Research Council.

\section{References}

1. CFS/ME Working Group. A report of the CFS/ME Working Group to the Chief Medical Officer. London: Department of Health; 2002.

2. Fukuda K, Straus S, Hickie I, Sharpe M, Dobbins J, Komaroff A. The chronic fatigue syndrome: A comprehensive approach to its definition and study. Annals of Internal Medicine 1994;121(12): 953-959.

3. Åsbring P, Närvänen A. Women's experiences of stigma in relation to chronic fatigue syndrome and fibromyalgia. Qualitative Health Research 2002;12(2): 148-160.

4. Anderson J, Ferrans C. The quality of life of persons with chronic fatigue syndrome. Journal of Nervous and Mental Disease 1997;185(6): 359-367.

5. Schweitzer R, Kelly B, Foran A, Terry D, Whiting J. Quality of life in chronic fatigue syndrome. Social Science and Medicine 1995; 41(10): 1367-1372.

6. Rakib A,White PD, Pinching AJ, Hedge B, Newbery N, Fakhoury WK, Priebe, S. Subjective quality of life in patients with chronic fatigue syndrome. Quality of Life Research 2005;14(1): 11-19.

7. Key D. One window. In: Munson, P, editor. Stricken: Voices from the hidden epidemic of chronic fatigue syndrome. New York: Haworth Press; 2000. pp 49-51.

8. Cox D. Chronic fatigue syndrome: An occupational therapy programme. Occupational Therapy International 1999; 6(1): 52-64. 
9. Cox D. Chronic fatigue syndrome: An evaluation of an occupational therapy inpatient intervention. British Journal of Occupational Therapy 2002; 65(10): 461-468.

10. Taylor RR. Quality of life and symptom severity for individuals with chronic fatigue syndrome: Findings from a randomized clinical trial. American Journal of Occupational Therapy 2004; 58(1): 35-43.

11. McDermott C, Richards SCM, Ankers S, Selby M, Harmer J, Moran CJ. An evaluation of a chronic fatigue lifestyle management programme focusing on the outcome of return to work or training. British Journal of Occupational Therapy 2004; 67(6): 269-273.

12. Aitchison C. From leisure and disability to disability leisure: Developing data, definitions and discourses. Disability and Society 2003;18(7): 955-969.

13. Schönherr MC, Groothoff JW, Mulder GA, Eisma, WH. Participation and satisfaction after spinal cord injury: Results of a vocational and leisure outcome study. Spinal Cord 2005; 43(4): 241-248.

14. Stebbins RA. Amateurs, professionals and serious leisure. Montreal: McGill University Press; 1992.

15. Stebbins, RA. The barbershop singer: inside the social world of a musical hobby. Toronto: University of Toronto Press; 1996.

16. Reynolds F. Conversations about creativity and chronic illness I: Textile artists coping with long-term health problems reflect on the origins of their interest in art. Creativity Research Journal 2003;15(4): 393-407.

17. Reynolds F, Prior S. 'A lifestyle coat-hanger': A phenomenological study of the meanings of artwork for women coping with chronic illness and disability. Disability and Rehabilitation 2003; 25(14): 785-794. 
18. Hart B, Grace V. Fatigue in chronic fatigue syndrome: A discourse analysis of women's experiential narratives. Health Care for Women International 2000; 21(3): 187-201.

19. Gray ML, Fossey EM. Illness experience and occupations of people with chronic fatigue syndrome. Australian Occupational Therapy Journal 2003; 50(3): 127-136.

20. Smith JA, Osborn M, Jarman M. Doing interpretative phenomenological analysis. In: Murray M, Chamberlain K, editors. Qualitative health psychology: Theories and methods. London: Sage Publications; 1999. pp 218240.

21. Smith J, Osborn M. Pain as an assault on the self: An interpretative phenomenological analysis of the psychological impact of chronic benign low back pain. Psychology and Health 2007; 22(5):517-534.

22. Cartwright T. 'Getting on with life': The experiences of older people using complementary health care. Social Science and Medicine 2007; 64(8): 16921703.

23. Mengshoel AM, Heggen K. Recovery from fibromyalgia: previous patients' own experiences. Disability and Rehabilitation 2004; 26(1): 46-53.

24. Bury M. Chronic illness as biographical disruption. Sociology of Health and Illness 1982; 4(2):167-182.

25. Whitehead L. Quest, chaos and restitution: Living with chronic fatigue syndrome/ myalgic encephalomyelitis. Social Science and Medicine 2006; 62(9): 2236-2245.

26. Viane I, Crombez G, Eccleston C, Poppe C, Devulder J, Van Houdenhove B, De Corte W. Acceptance of pain is an independent predictor of mental wellbeing in patients with chronic pain: Empirical evidence and reappraisal. Pain 2003; 106 (1-2): 65-72. 
27. Caldwell L. Leisure and health: Why is leisure therapeutic? British Journal of Guidance and Counselling 2005; 33(1): 7-26.

28. Hyland M, Sodergren S, Lewith G. Chronic fatigue syndrome: The role of positivity to illness in chronic fatigue syndrome patients. Journal of Health Psychology 2006;11(5): 731-741.

29. Clarke J, James S. The radicalized self: The impact on the self of the contested nature of the diagnosis of chronic fatigue syndrome. Social Science and Medicine 2003; 57 (8): 1387-1395.

30. Collinge W. Recovering from chronic fatigue syndrome. New York: Putnam; 1993.

31. Kvale S. InterViews: An introduction to qualitative research interviewing. London: Sage; 1996. 